\title{
SERVICE ORIENTED ARCHITECTURE GOVERNANCE IMPLEMENTATION IN A SOFTWARE DEVELOPMENT PROJECT AS AN ENTERPRISE SOLUTIONS
}

\author{
Ryan Rahmansyah and Ford Lumban Gaol \\ Department of Magister Information Technology, \\ Bina Nusantara University, Jakarta, Indonesia
}

Received 2013-09-09, Revised 2013-11-18; Accepted 2013-11-19

\begin{abstract}
In this journal, discussed the way Service Oriented Architecture (SOA) governance applied in a company that is made to meet the business needs related with software development projects. The analysis is based on the latest information from the company and the way in which the system implemented based on several methods and also references from existing best practice. Various methods used in building this kind of system, however, is used in the design of SOA governance that perform overall management within the organization. To analyze the application of SOA, used the method of SOA maturity that will be handle in the application and subsequent assessment.
\end{abstract}

Keywords: Architecture, SOA, Governance, Enterprise, Maturity System

\section{INTRODUCTION}

Along with the rapid development of technology, particularly in the world of information technology, important for industry players, such as the company, to have a system architecture which the user's desired or accepted by related industry. Architecture should also be able to offer a tool that make the work planning that operates in parallel with other components, especially the business section. That the architecture is expected to see the other aspects apart from the functional point of view IT course. Lack of IT-architectural that can support this Enterprise Architecture makes it difficult to protect the company against quickly and dynamically business changes in the existing IT environment. Architectural techniques made is expected to reveal the characteristics of the system and in accordance with the business you want to work.

\subsection{Why is it Needed}

Complexity of existing businesses cause investments in the IT work increase since the number of multiple services that must be developed by a company, many Corresponding Author: Ryan Rahmansyah, Department of Magister Information Technology, Bina Nusantara University, Jakarta, Indonesia existing services led to the duplication or repetition in them. Therefore it is perceived not effective enough for a company to carry out software development projects where there is a lot of repetitive service and not used again. The high level of development of IT projects within the company should also be considered carefully, so companies have no difficulty in handling the demands of the market. It also affects the system already built before, system integration becomes difficult and each existing service would cost the company as a whole system.

\subsection{Impact Occurs}

Such situations, make one of the companies in Indonesia implementing SOA as their internal architecture in a further application will be discussed in this journal. The company is engaged in the broad field of business and working with several partners to provide IT solutions require a good and acceptable service by the market. This has resulted in difficulties because many business and service are repeated continuously and feared the duplication of existing services. Services within the company itself is centered on a large software 
development and infrastructure. Thus, this service can be burdensome that many data storage and integration process due to growing business. The use of SOA as an architectural solution platform is expected to support existing businesses and is expected to help the company to better accommodate the change by providing the flexibility to use IT resources better (Aradea, 2011).

\subsection{Related Background Knowledge}

There are few of related knowledge which is use as a proponent in this journal, in this section also discussed several areas that are helpful in work on the implementation of the system.

\subsection{Service Oriented Architecture}

Service Oriented Architecture is an architectural model of the system that create and use business processes in the form of service packs throughout its life cycle. As the name implies, this architecture emphasizes on the components that provide a particular type of business or service specific services. Broadly speaking, SOA is an approach to design an application using the back of a component-the component that already exists (Hurwitz et al., 2007). In the IT field, the term SOA service developed within the scope of the use of software to support the needs of the user. SOA can thus act as information technology architecture that can support a variety of applications to exchange data and participate in business processes related (Chen et al., 2008).

In an IT environment or using SOA environment, the process in it available as independent services that can be accessed without knowledge of the implementation of the platform in the back or in different sources. Thus allowing the formation of the architecture of open standards-based framework that enables enterprises to mutually integrate previously fragmented data become integrated in one piece. This makes the SOA as distributed components that can be used in a variety of programming languages and so many platforms (Adam et al., 2012).

Service Oriented Architecture said to be a standard development process from variety of interfaces that are used as supporting aids in accessing the application to access the different business functions, as well as in it connects the various core business of existing backend systems. This function becomes essential and important to other business systems company incorporated in the ecosystem, thus standardizing the interface can be used widely in a company and can handle different applications both in terms of business or functional (Seshadri, 2007).
Later in this section, will be shown how to work and the concept of SOA, introduction of the service and its operation in web service.

\subsection{SOA Concepts}

SOA built in a modular type. This modular approach is actually not something new. In the present programming techniques such as Object Oriented Programming (OOP), a modular approach has been put forward in the development of applications. But what makes SOA different is a component or service is constructed and interact with each other freely and loose coupled. With nature of loose coupled, a service can be invoked by other program without the need to pay attention to the caller program where the called service location and what platform/technology is used by the service (Haki and Wetland, 2010).

Described in Fig. 1 (quoted from SOA meta-model, The Linthicum Group, 2007), an example of SOA as a support system of service that the company developed. SOA where it will connect with a lot of other services that will be shared services that can be accessed by anyone. Service set up and managed from the data or from a derivative of existing systems.

So that SOA would be desirable design principles for building distributed systems that believed in delivering its service functionality, with the added emphasis on loose coupling between service users (Krafzig et al., 2005).

The workings of the SOA using paradigm from find-bind-execute process as shown in Fig. 2 (quoted from J2EE Platform Web Services, 2004, Lai, 2004). Illustrated in that figure the cycle of interaction service in SOA system architecture. In phase 1 , the service provider publishes its service to the public registry. In phase 2 , service consumer search for the required services to the public registry. Phase 3 , the registry will be giving out the response form available in the list of the registry service that comes with the address information, the way calling service, the return that will be obtained and identify the protocol used. Later in the phase 4 , service will gives response (Zhang and Goddard, 2007).

Through this process can be obtained the ease of data retrieval process and in getting access to the necessary registry. In addition, there is a separation between the user represent by Service Customer with the service provider represent by Service Provider. The separation process also strengthens the security for the system are already diregistry cannot be accessed by anyone. Separation of the role itself can strengthen business processes in order to work more optimally (Rosen et al., 2008). 


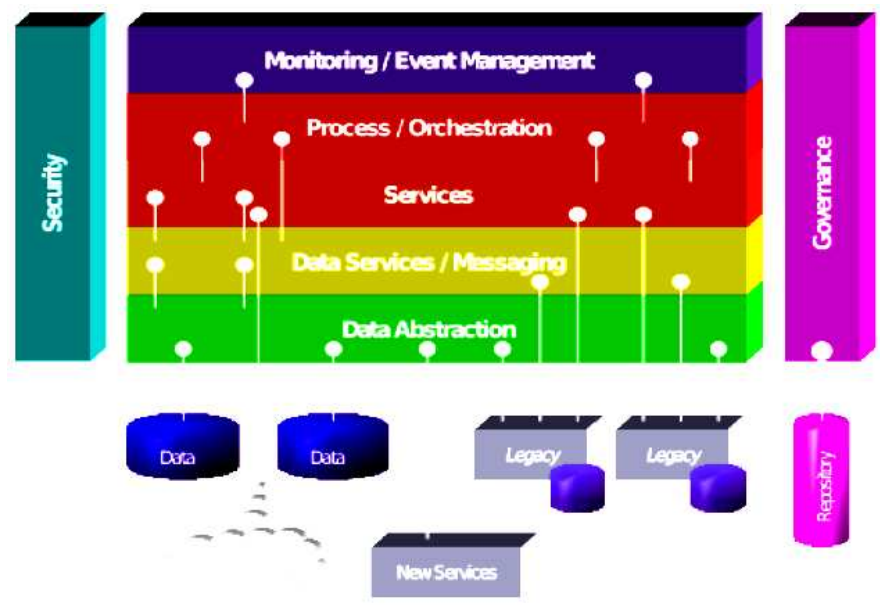

Fig. 1. SOA Architecture

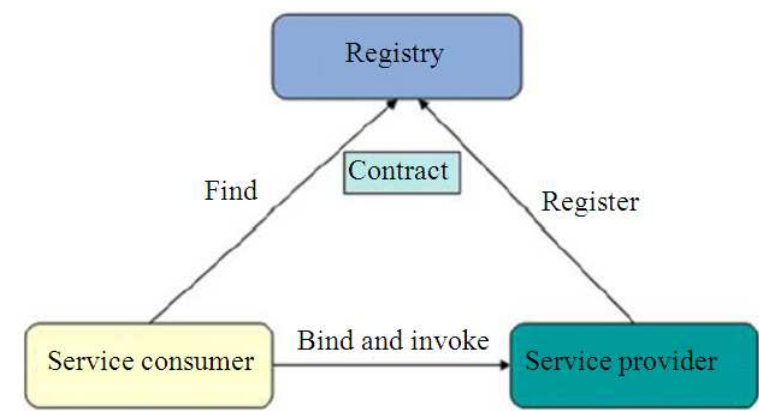

Fig. 2. Process in SOA

\subsection{The Concepts of Service in SOA}

Service form a group of independent functions that are not directly related to each other rather than to the service interface. This service in SOA can run on various operating systems, used in various locations as well as written in various programming languages. One common device used in this architecture is service bus enables communication between the services through a service interface. Self service interface is a standard method of communication that anyone can use, regardless of who makes it or who is providing it. Service bus will hide part of the service that communicates with the application.

In Fig. 3 (quoted from Toward Realization of SOA, 2006) shown instances where there is a bus service between the role of workflows that are used with an existing service.

This service processes become vital, where the core of SOA is itself contained in the service. They form a set of service components that will communicate with each other. Service was also that would later become the basis of an application using SOA architecture. Where the approach will be developed to describe and manage each service to be appropriate and useful. Existing services must also be aligned with business functions that are developed, so that even though the service grow bigger in the future, IT architecture using SOA can follow business processes well.

\subsection{Web Service}

Web service is a method of communication between two electronic devices over the World Wide Web. A web service implemented software functions that are provided on a network address via the web or cloud, the service itself is a service that has always lived as in the concept of a computer utility. Web Service can be implemented in the internal environment (Intranet) for the needs of integration between application systems or on the external environment (the Internet) to support the application of Business to Business (B2B). Web Service Definition by W3C itself is "A Web service is a software system designed to support interoperable machine-to-machine interaction over a network. It has an interface described in a machine-processable format (specifically WSDL)" (Khoshafian, 2006).

This is what causes the cycle process in web service will be the same as SOA. The process of web service itself is based on SOA architecture is implemented using the infrastructure of the requester entity that can bind and use the web service in several ways, but the velocity of interaction in the web service will always be in accordance with current turnover of SOA (Josuttis, 2007). 


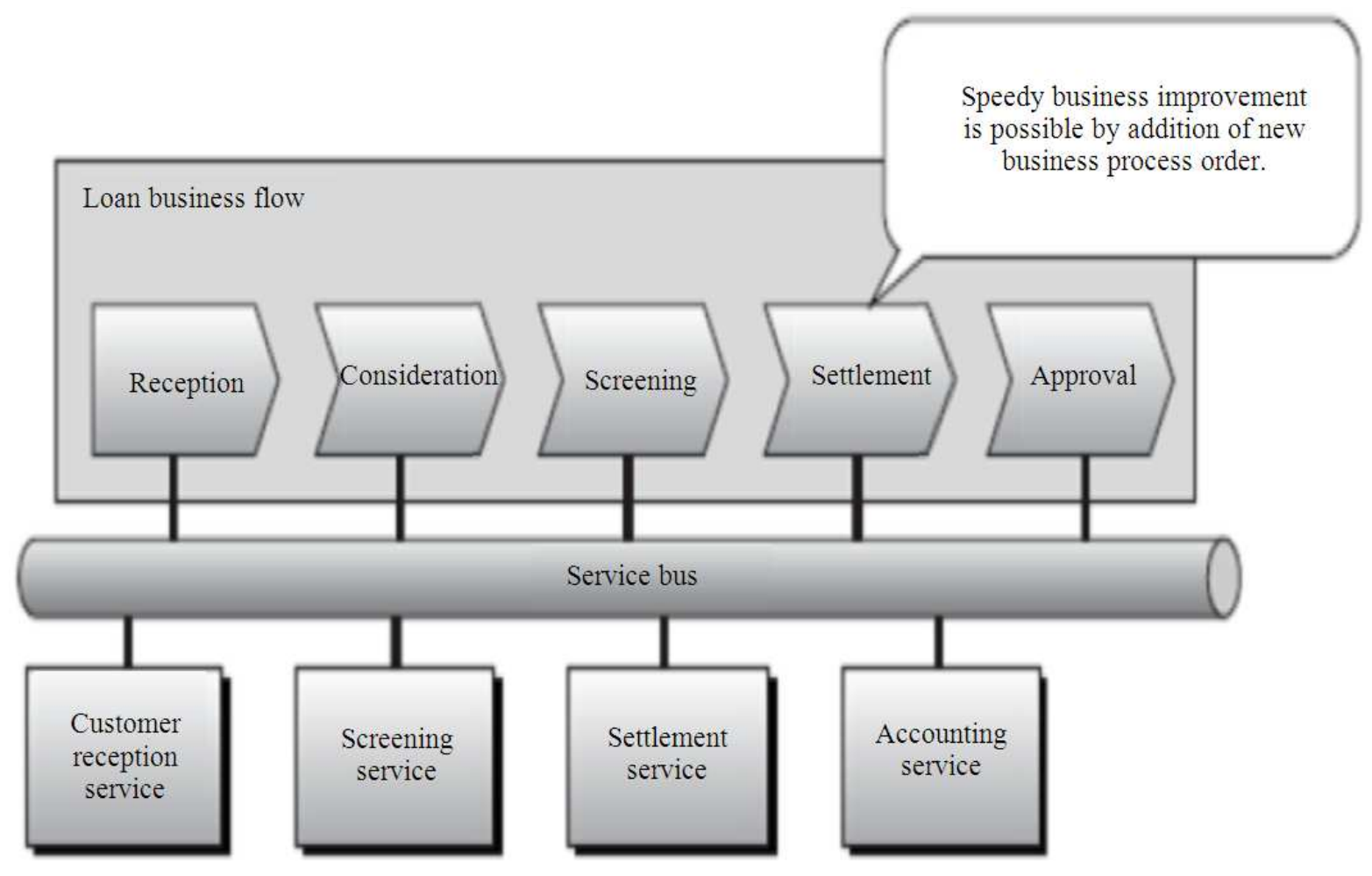

Fig. 3. Service related in SOA

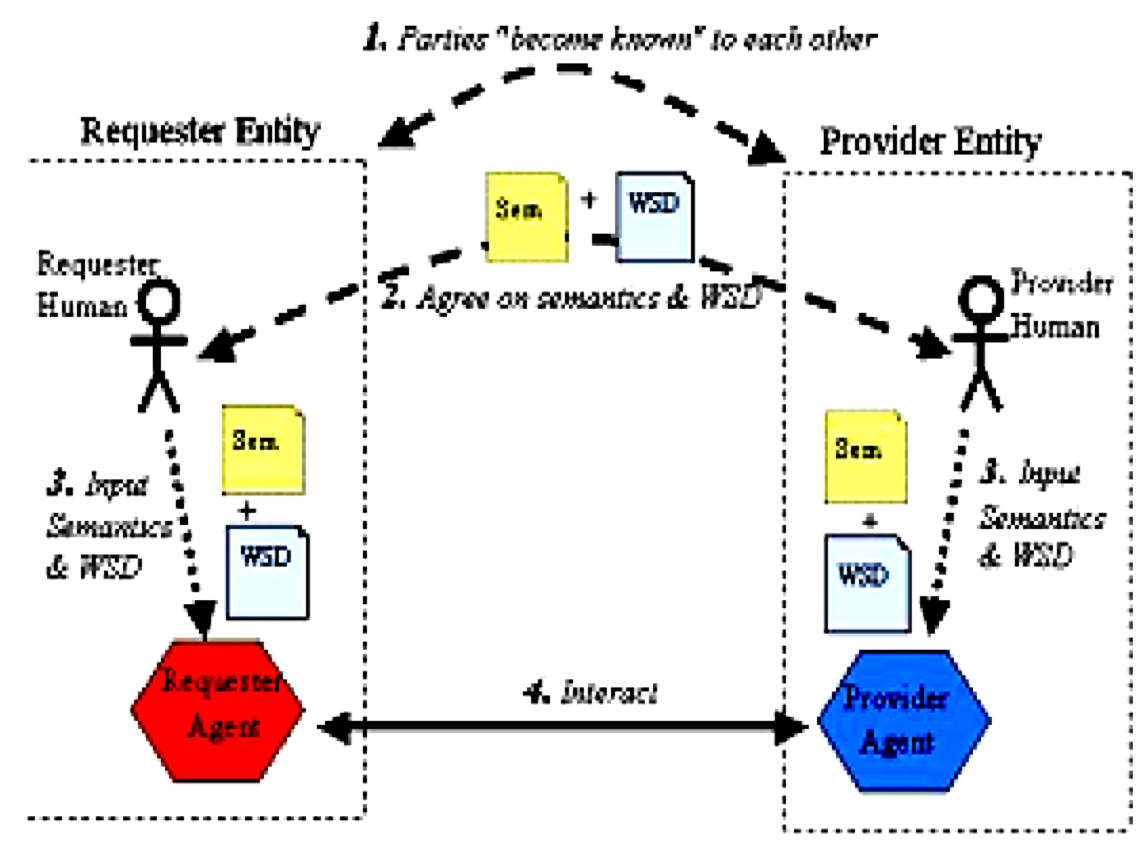

Fig. 4. Web Service process 
This process is described in Fig. 4 (quoted from W3C: Web Service Architecture, 2003), where in the process will involve the requester Entities and Provider Entities, both of them should know each other, or at least know the other one. Both of provider and requester should agree on the semantic Web Service Description and would regulate interaction between agents (software or hardware pieces that send and receive messages) from the requester and provider. Expected and semantic service descriptions based on the requester and provider agencies that between them to facilitate the exchange of messages.

\subsection{SOA Governance}

SOA governance is the process of coordinating the activities of development services, particularly those undertaken a large business entity. It is necessary to maintain consistency and interoperability between different services. Worth underscoring that everyone involved in the company that uses SOA despite being in different divisions or locations need to know what services are available. So the reuse of code and processes needed to run well. Good SOA governance will also reduce the risk of service incompatibility and development efforts that are too excessive. Should be seen also that SOA governance is not just for the IT team alone, but also involves the business interests of all stakeholders (Newcomer and Lomow, 2005).

In the context of SOA governance, that is often misunderstood by many people. SOA governance is often regarded as a service lifecycle governance in itself and focus on the development of service regardless of the success of the business goals and objectives of the SOA conducted itself. SOA development must be aligned with business objectives, minimize risk later in life and also adapts to the context of existing organizations. SOA governance can be defined as the interaction between policy (What), decision makers (WHO) and the process (how) to ensure the success of SOA as described in Fig. 5 (quoted from SOA Governance: Framework and Best Practice, 2007).

'What' variable signifies what decisions should be made for a more effective management, 'Who' means anyone who must make decisions and who has the right to provide input and 'How' refers to how the process will be approved and implemented. All these things lead to SOA strategy, so it will be in line with the existing business. Policies and supporting processes will be important so that communication runs smoothly not only in one direction only and the supervision of the implementation has been done. This is what is at the core of SOA governance, to implement policies and procedures to ensure the timely passage of the system and execution in accordance with the original plan.

\subsection{Methodology and Examination of Implementation Approach}

In order to solve the problems discussed in the previous section, in this section will be discussed regarding approaches and methods are done in applying SOA in the associated company, the scope of the discussion is limited in software design and development projects.

The methodology made based on a series of work processes that established to realize a service solution. Work process is organized into a concept that has been approved by the company. This idea is supported by multiple sources of information such as literature, articles, journals and best practice that has been carried out by well-known companies such as IBM, plus observation and field research in the form of surveys and interviews related to the company. The resources then tabulated into an implementation method to approach the application of the concept of SOA governance and maturity analysis system for further processing (IBM, 2005).

Further, it will also include the steps undertaken to examine the approach in order to implementing the architecture in enterprise systems. Which is then divided into several steps below.

\subsection{Determine Key Informants}

This process is used to determine the core of IT staff personnel who serve and know in detail the processes in the architecture under study to obtain a general overview and formulation of the problems that occur in the company.

\subsection{Data Collection Techniques}

By using the exploratory interview techniques to obtain the necessary data. Literature study was also conducted to study and collect data that are theoretically based on the literature and reference books as well as secondary data from the internet relating to SOA.

\subsection{Identification and Analysis System}

In this process, the researchers looked at how the performance of the application and analysis how the processes of data service occur. In addition, researchers also looked at how the process in implementation of each project as well as the processing of applications made. 


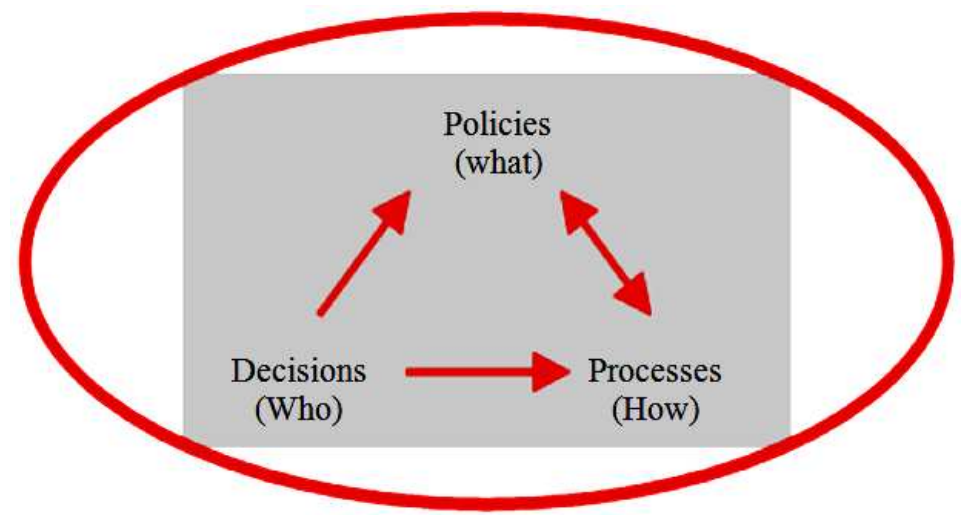

Fig. 5. SOA Governance plot

\subsection{Service Modeling and Restructuring Process}

The next step is carried out modeling of existing service infrastructure to support the development of implementing SOA. The technique used is SOA governance and with the help of the application design and sample process to exchange data between two applications so that business processes can be well defined.

\subsection{Assessment and Integration}

Application and integration testing is used to see the level of success in the service which takes place between the application has been determined. Testing is done by sampling a specific application for the data exchange process. It also conducted a validation process that takes place.

\subsection{Documentation Report}

Process will be documented so easily done in further development if required at any time to a similar process.

\subsection{General Overview in Enterprise and the Scope of the Market}

The Company operating in the field of IT solution service started expand their business processes since 2009. Where it has an impact on the company's mission which initially providing hardware maintenance services and then provide comprehensive IT solutions for end-toend and software development for client companies. As the development of the new business demands the development of new processes with emphasis on functional processes in order to form a more focused IT solutions with a better service. The development would have a wide impact on the company's internal and external. Where the company is required fast response in the execution of existing projects.

Along with this, company performed exploration in market segments supported by them, in order to get potential customers and potential new business that allows grouping based on criteria such as similarity of business and service needs. The company will analyze each client, the scope of the industry followed and the product who want to produced. Thereafter will be set up several design related by industries and associated market share in order to facilitate the further development of the process in case found similar clients. Need to be seen that the focus shouldn't only into one industry and clients as well, but also see the possibility of another organization or institute and to participate may participate in the development of further cooperation.

Through an analysis of the way the process has been carried out by the company in dealing with projects that already exist, some processes that are perceived to be ineffective. Top position where that act as service manager feel the difficulties in adapting a software development project that is divided into several areas and industrial areas are not the same. Each of these industries also have different levels of different difficulty levels so that the gap of quality projects.

Distribution process based on the level of difficulty and the industry which then leads to the design of a new scheme that has the same design service in accordance with a provision in spite of being in different industries. This provision alone will then be made in the Business Process Modelling governing the distribution and restructuring projects based on this service. With the division of this service will create a new modeling that make arrangements in each division of a process into a separate service in SOA envelope. Making it easier for companies to implement rapid-development when faced with a new project. 
Changes made to the company's SOA implementation is also affecting the way organizations and employees in work. It is also likely to lead to the replacement of the structuring of the project with the establishment of a new management model and viable organization and works in the pragmatic way. Changes are used to facilitate and automate several processes and policy so that it makes employees more comfortable in the new structure.

Further changes in the presence of Excellness Center (COE), which contains a special team of each project. This allows the company to focus more on existing resources and focusing on innovation that can be generated as well as ensure the success of the project. $\mathrm{COE}$ is also set up to reduce the complexity in the execution of SOA. This dedicated team will support each team's project for any further controlling in term utilization of SOA in the enterprise. Given the role of the $\mathrm{COE}$, among others, in terms of teaching SOA skill in the team's project and understanding of the basis of the programming of each project, to enable the development of the company's overall competence.

\subsection{SOA Utilization Strategy}

The use of SOA in the enterprise using SOA governance where the system exist in an effort to focus the company's business success and realize the benefits of SOA adoption itself. So it will be closely connected with the business objectives and implementation, reducing the risks associated with SOA system and matching in the context of the overall governance framework IT organization. Based on this, the use of SOA is based on a strategy to ensure that the business is in line with the developed and developing concrete ideas that expected from SOA investments itself.

As a form of utilization strategy of SOA in the enterprise, there will be illustrated in the Fig. 6 below the form of a roadmap arranged become the step in order to produce successful implementation of SOA.

From the roadmap above, it can be seen that outlines strategies implemented in the company and the target during a certain period (two to five years) and the certainty that businesses can be run in accordance with the utilization of SOA. From the chart, also shown in the gradual process of building the necessary skills over a period of time, increase the maturity of SOA and existing systems as well as enabling the development of more software development projects in a more efficient and adaptable to change. So the core of SOA governance to enforce the policies and procedures to ensure the adoption of SOA can be completed on time according to the agreed roadmap.
In the utilization in order to achieving these objectives based on roadmap, made understanding the key aspects that must be addressed in the company. Here's is a key aspect who be used as the process of core within the company which need to be managed using SOA. That core process divided into eight business areas: System Engineering and Operational, Finance, Software Engineering, Human Resource, Portfolio Management, Document and Information, Database and Project Management Officer.

\subsection{SOA Governance Model}

Adoption of Service Oriented Architecture in the company introduced a new asset, process, technology, standardization, role and others require the application of policies and procedures of good governance. Hence, the model offered a framework for defining and building a proper SOA governance. Framework adapted to the existing organizational structure, scope and conformity with the vision and mission of the company. These utilization are not only focused on the aspect of SOA development, but also the need to realize the company's strategy. Furthermore, this governance should be developed so as to make the investment of existing assets into more value for the company.

Framework for SOA governance is divided into 5 groups that are connected to each other in 3 layers consisting of: Initiation Governance, Organization Governance, Technology Solution Lifecycle Governance, Process Lifecycle Governance and Delivery Governance. More can be seen in Fig. 7 below.

Utilization of SOA governance is formed of 3 IT processes in general, i.e., Input, Process and Output. The third thing is the core layer of the framework. In input, multiple references and directives included intertwined in the process so there is no way you want to target. In the process, this section is divided into the 3 scopes are: organization, technology and process service. It is made to strengthen the company's needs in creating policies and good governance. The last section describes the output results to be addressed in the application.

In a study of the implementation of SOA Governance at one company in Indonesia, the business processes that will be the focus of attention is how to manage the two (or more) of software development projects are on topics previously mentioned to be the main business of the company. It consists of structuring the project within the company as well as the correlation with the Service Oriented Architecture. Service will be broken down in various line of business are placed in the repository which is then deployed in the project using SOA concepts. 


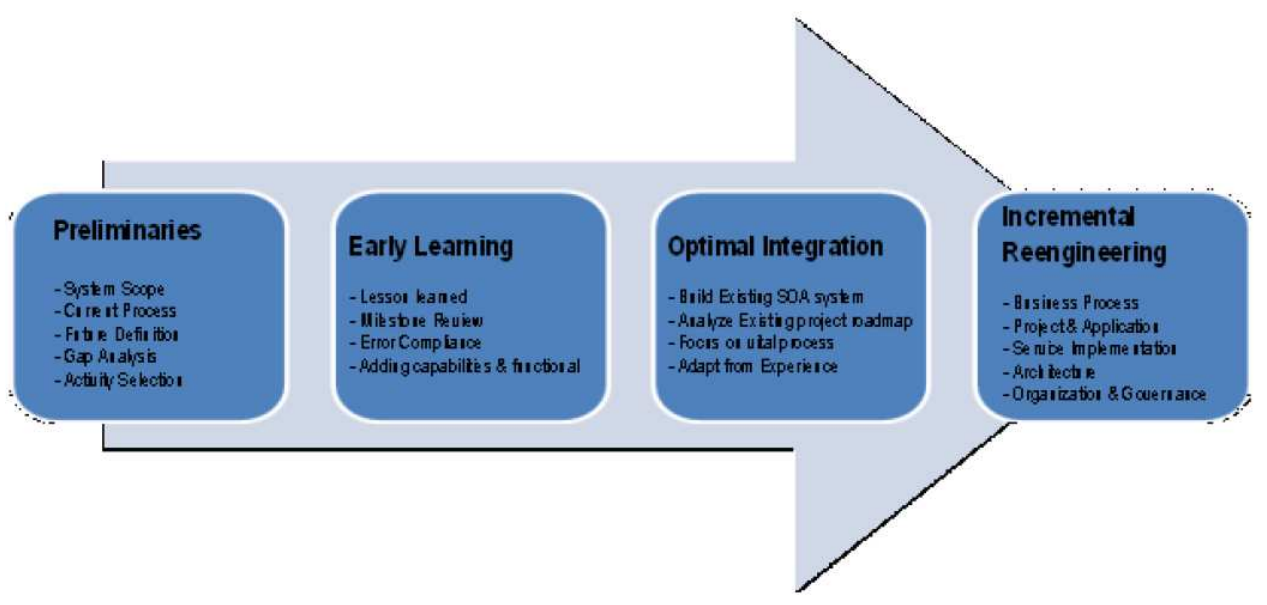

Fig. 6. SOA Roadmap

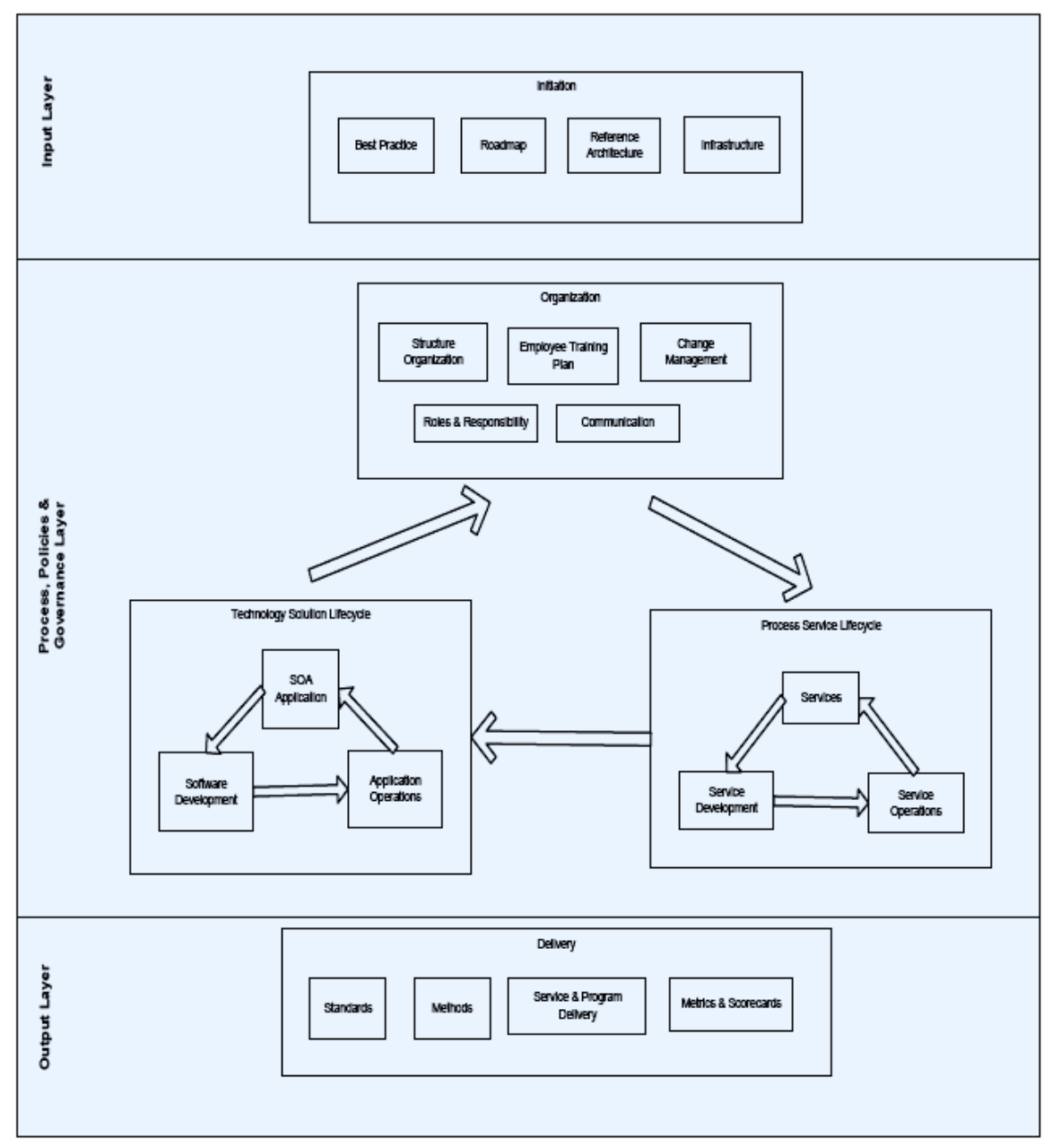

Fig. 7. SOA Governance framework model 


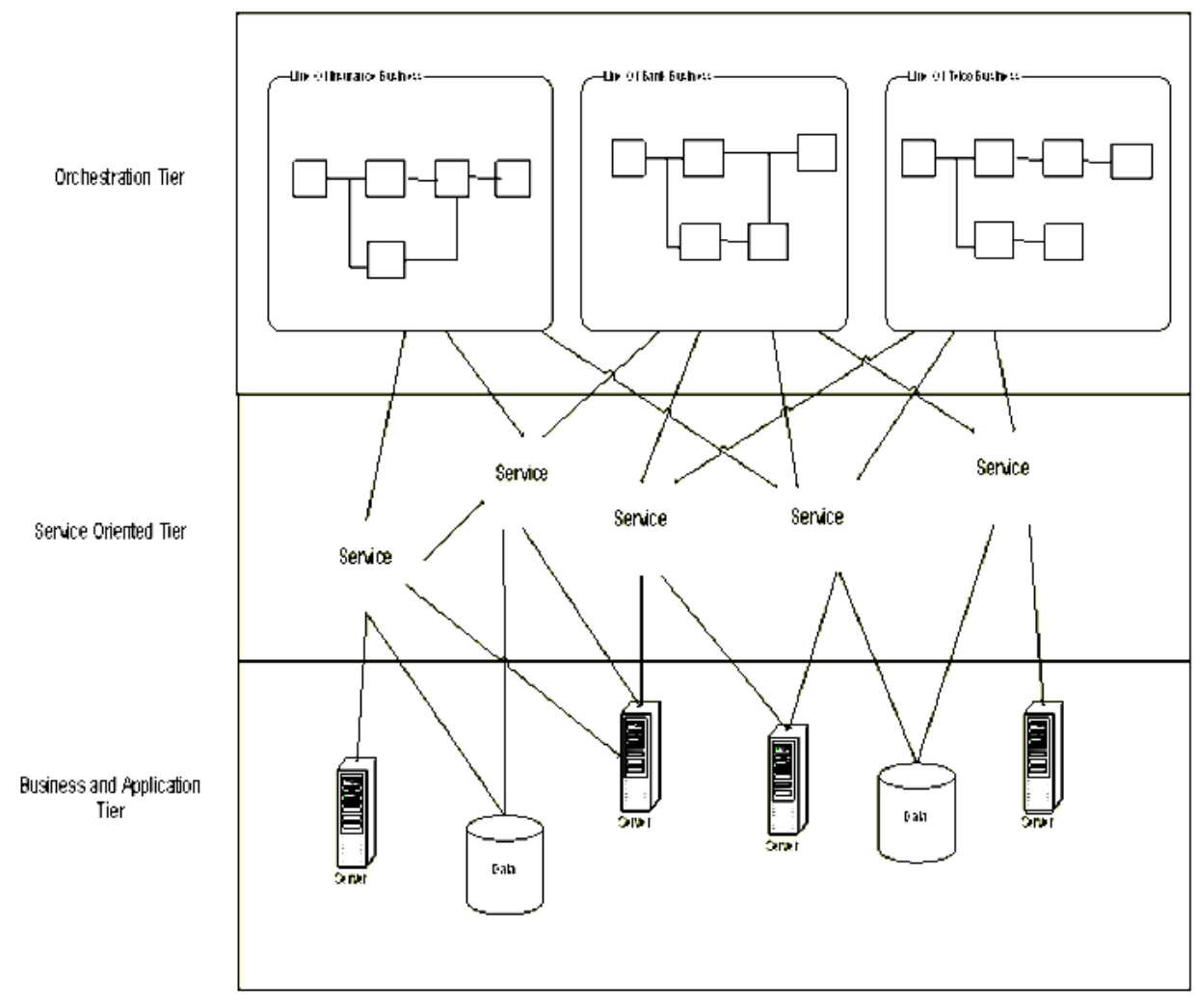

Fig. 8. Business Process within the company

Broadly speaking, the process starts from the business area and continues to service the area. Line of business groupings provided by the company earlier used as a benchmark. Then be translated in the form of service which coupled with a combination of several parameters. The goal is to reduce the similarity of data and service. Therein will be added to the convergence of data that offer services to users regardless of the underlying platform the previous system.

Embodiment in the business process outlined in Fig. $\mathbf{8}$ below, so that the representation model of the business is run so that each running process can be implemented at the business service.

A major challenge in business processes management requires a flexible and personalized service for end-users and shorter time in producing software. Thus required the implementation and technical infrastructure that makes information systems more simple, flexible and open to provide access to safe and reliable for the company. Framework using an open service delivery, so service was opened to the internal environment, it is intended as the phase of development, deployment, monitoring, executing and other multiple processes in the life cycle will be centered on the user application.

This process covers the entire value of existing business lines, across internal and touch all the relevant actors in it. Service produced by the company are distributed to all levels and across the boundaries that exist within each project. Collaboration is required from each project team in the development and utilization of service combined service itself. Once a collection of line-of-business incorporated in the collaboration. The unification of the integration project will generate overall profits of the company, not just for one or two related projects.

The researcher also empowering a new structuring of the company to meet the increased level of collaboration and better governance so that the decisions required by architects and project teams obtained more quickly. The implementation starts from the top in a managerial position to encourage adoption and commitment to the smallest element of the project team. This is done to monitor and manage existing policies in the course of the SOA. 


\section{CONCLUSION}

SOA is the latest part of the Enterprise Architecture should be driven by strategy and tactics to achieve the goals and objectives of the business. To meet these objectives, companies should establish better alignment between some aspects contained in the company include architecture, technology infrastructure, information and data, portfolio, project implementation, human resources as well as some operational components.

Implementation of SOA governance in corporate is built to add value to the assets already owned by the company earlier, especially in the aspect of software development. The biggest benefits of the SOA investment can occur because the company can maximize all local investments and start maximizing all assets across the enterprise. In addition, there are some benefits that can be maximized by companies, such as: scope of user-applications developed by company is wide, the human resources are pretty much in the company and the concept of SOA science that has been applied in the client.

One view of the keys to successful implementation of SOA in the enterprise that is the active role that involved in the construction of the first attempt. So that SOA will be able to support increased business so the system have harmony with existing IT. SOA itself is felt to create alignment between business and IT systems that exist and then creating a flexibility. Because in this modern era of business processes developed by a company growing faster every day and global competition requires an architecture that can overcome it. Active role of the company, especially in the managerial level in actively supporting the implementation of this system also helps the process further, good policies and rules applicable to the better.

\section{REFERENCES}

Aradea, A., 2011. Integrasi arsitektur dan manajemen layanan ti untuk pencapaian fleksibilitas teknologi informasi pada organisasi. Seminar Nasional Aplikasi Teknologi Informasi, Indonesia.

Adam, B., J.B. Weissman and V. Hemert, 2012. Reducing data transfer in service-oriented architectures: The Cir-culate Approach. IEEE, US. 5: 437-449. DOI: 10.1109/TSC.2011.23
Chen, D., G. Doumeingts and F. Vernadat, 2008. Architectures for enterprise integration and interoperability: Past, present and future. Comput. Indus., 59: 647-659. DOI: 10.1016/j.compind.2007.12.016

Haki, M.K and F.M. Wetland, 2010. Service-oriented business-IT alignment: A SOA governance model. AISS, 2: 51-60.

Hurwitz, J., R. Bloor, C. Baroudi and M. Kaufman, 2007. Service Oriented Architecture for Dummies. 1st Edn., John Wiley and Sons, Hoboken, ISBN-10: 0470116781, pp: 360.

IBM, 2005. A comprehensive enterprise social service system. State Of Lousiana Department of Social Service.

Josuttis, N.M., 2007. SOA in Practice: The Art of Distributed System Design. 1st Edn., O'Reilly Media, Inc., Sebastopol, ISBN-10: 059655155X, pp: 344.

Khoshafian, S., 2006. Service Oriented Enterprises. 1st Edn., Auerbach, Boca Raton, ISBN-10: 0849353602, pp: 464.

Krafzig, D., K. Banke and D. Slama, 2005. Enterprise SOA: Service-Oriented Architecture Best Practices. 1st Edn., Prentice Hall Professional, Upper Saddle River, ISBN-10: 0131465759, pp: 382.

Lai, R., 2004. J2EE Platform Web Services. 1st Edn., Prentice Hall Professional, Upper Saddle River, ISBN-10: 0131014021, pp: 578.

Newcomer, E. and G. Lomow, 2005. Understanding SOA With Web Services. 1st Edn., Pearson Education India, ISBN-10: 8131711137, pp: 476.

Rosen, M., B. Lublinsky, K.T. Smith and M.J. Balcer, 2008. Applied SOA: Service-Oriented Architecture and Design Strategies. 1st Edn., John Wiley and Sons, Indianapolis, ISBN-10: 0470390816, pp: 700.

Seshadri, G., 2007. Case study implementing SOA: Methodology and best practices. IGI Global.

Zhang, S. and S. Goddard, 2007. A software architecture and framework for web-based distributed decision support systems. Decision Support Syst., 43: 11331150. DOI: $10.1016 /$ j.dss.2005.06.001 